\title{
BMJ Open Multiple myeloma and physical activity: a scoping review
}

\author{
Lee Smith, ${ }^{1}$ Orla McCourt, ${ }^{1}$ Malgorzata Henrich, ${ }^{1}$ Bruce Paton, ${ }^{2}$ Kwee Yong, ${ }^{3}$ \\ Jane Wardle, ${ }^{1}$ Abigail Fisher ${ }^{1}$
}

To cite: Smith L, McCourt 0 , Henrich M, et al. Multiple myeloma and physical activity: a scoping review. BMJ Open 2015;5:e009576. doi:10.1136/bmjopen-2015009576

\section{- Prepublication history for this paper is available online. To view these files please visit the journal online (http://dx.doi.org/10.1136/ bmjopen-2015-009576).}

Received 31 July 2015 Revised 28 October 2015 Accepted 2 November 2015

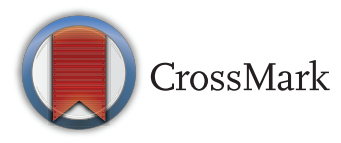

${ }^{1}$ Department of Epidemiology and Public Health, Health Behaviour Research Centre, University College London, London, UK

${ }^{2}$ Institute of Sport Exercise and Health, University College London, London, UK

${ }^{3}$ Research Department of Haematology, Cancer Institute, University College London, London, UK

Correspondence to Dr Lee Smith; lee.smith@ucl.ac.uk

\section{ABSTRACT}

Objectives: Multiple myeloma is the second most common haematological cancer. A growing body of literature is emerging that investigates the role physical activity plays in all stages of multiple myeloma (prevention and survivorship) and to date no attempt has been made to collate and understand this literature. Therefore, this scoping review aims to (1) outline what is already known about physical activity in all stages of multiple myeloma (2) map the literature on physical activity and multiple myeloma and (3) identify future directions for research.

Design: Scoping Review.

Data Sources: Searches were carried out in May 2015. Searchers were conducted in PubMed, Web of Science, SPORTdiscus and MEDLINE.

Eligibility criteria for selecting studies: To be included studies had to report original data, investigate physical activity per se or physical activity correlates and multiple myeloma or smouldering multiple myeloma.

Results: A total of 19 papers received full screening, 5 of these papers were excluded. This review identified three journal articles relating to the role of physical activity in the prevention of multiple myeloma, nine papers were identified in the treatment of multiple myeloma and two on smouldering multiple myeloma.

Conclusions: The search identified that the literature surrounding multiple myeloma and physical activity is very limited. We encourage those designing new cohort studies to allow for future assessment of associations between physical activity and onset of multiple myeloma and smouldering multiple myeloma, as well as the potential role that physical activity plays in the progression from smouldering multiple myeloma to multiple myeloma. Second, we encourage the design and investigation of gender and treatmentspecific physical activity interventions in patients with multiple myeloma. Finally, we highlight the need for more randomised controlled trials to evaluate the impact of different types, frequencies and intensities of physical activity on various health parameters in multiple myeloma survivors.

\section{INTRODUCTION}

Multiple myeloma

Multiple myeloma (MM) is the second most common haematological cancer, resulting

\section{Strengths and limitations of this study}

This is the first attempt to collate literature surrounding physical activity and multiple myeloma.

- There has been little research on physical activity for multiple myeloma and even less for smouldering multiple myeloma.

- This review has identified several avenues for new research on multiple myeloma and physical activity.

- This review is limited by a shortage of research.

from the accumulation of malignant plasma cells in the bone marrow. ${ }^{1} \mathrm{MM}$ is responsible for approximately $1 \%$ of all cancer cases globally and in the UK, and incidence rates have increased in the UK since the mid-1970s (http://www.cancerresearchuk. org). There is no known cure for MM, but current treatment modalities can control the disease for prolonged periods. MM is generally a disease of older adults, and approximately two-thirds of patients diagnosed are aged 65 years or more. ${ }^{1}$ Survival is variable, but about a third of adult patients with MM diagnosed in 2010-2011 in England and Wales are predicted to survive for 10 or more years (http://www.cancerresearchuk.org). Recent analyses have shown promising evidence of improved outcomes, likely owing to increasing use of novel treatment agents used during initial treatment such as thalidomide and bortezomib. ${ }^{2}$ MM is associated with a number of complications which include haematological complications (anaemia, bone marrow failure, bleeding disorders), bone complications (pathological fractures, lytic bone lesions, hypercalcaemia related to excessive bone turnover), renal insufficiency, compromised immune function and neurological complications (eg, spinal cord and nerve root compression and cranial nerve compression, often related to base of skull lesions). ${ }^{3}$

Almost all patients with MM will have had the precursor smouldering multiple 
myeloma (SMM); SMM is characterised by the presence of MM cells in the bone marrow and M-proteins in the blood, but without evidence of organ damage. Individuals with SMM have a $10-20 \%$ risk of developing MM each year. ${ }^{4}$ Recent recommendations by the International Myeloma Working Group (IMWG) identify a group of patients with SMM who are at a high risk of progression to MM, for whom systemic therapy is recommended.

Improved treatments for MM means patients with the disease are living longer, but with the cumulative burden of bone disease, compromised immunity and treatment-related toxicities, that prevent the return to good quality life. MM survivors often suffer from the sequelae of bone destruction: persistent deformities, chronic pain, reduced mobility and physical functioning. It could be hypothesised that participation in physical activity may be a beneficial strategy to improve reduced mobility and physical functioning. Hence there is an increasing need for non-pharmacological strategies for the management of this patient group. ${ }^{2}$

\section{Physical activity and the prevention of cancer}

There is evidence from over 100 epidemiological studies, that routine physical activity is associated with the reduction in the incidence of some cancers (eg, breast and lung; see reviews by ${ }^{5}$ ), there also appears to be a dose-response relationship, ${ }^{7}$ that is, the higher the intensity of routine physical activity the greater the protective effect against cancer. However, the benefits of physical activity may vary between cancer type, for example, a recent meta-analysis on physical activity in relation to risk of haematological cancer identified 23 papers and showed non-significant associations. When comparing high versus low physical activity levels, the RR for non-Hodgkin's lymphoma was 0.91 (95\% CI 0.82 to $1.00)$, for Hodgkin's lymphoma it was 0.86 (95\% CI 0.58 to 1.26 ), for leukaemia it was 0.97 (95\% CI 0.84 to 1.13 ) and for MM it was 0.86 (95\% CI 0.68 to 1.09$).{ }^{8}$

\section{Physical activity and cancer survivors}

Focus has also turned to physical activity for cancer survivors. Physical activity has been shown to be safe and feasible during cancer treatment and can improve physical functioning and quality of life, as well as reduce fatigue. $^{9}$ A recent meta-analysis of high-quality controlled trials ${ }^{10}$ identified the importance of regular participation in physical activity for the health of cancer survivors. The analyses showed that physical activity has been found to improve aerobic fitness, muscular strength, functional quality of life and self-esteem, and reduce anxiety. However, the majority of studies identified investigated solid tumours and very few investigated haematological cancers. A number of reviews have also been carried out on the role of physical activity in the survival of a number of specific cancers, including breast, lung and prostate. ${ }^{11-13}$ A growing body of literature is emerging that investigates the role physical activity plays in all stages of MM (prevention and survivorship) and to date no attempt has been made to collate and understand this literature.

\section{Aim}

Scoping reviews are relatively novel, compared to other review types (eg, systematic) and are growing in popularity. Scoping reviews allow the researcher to (1) clarify working definitions and conceptual boundaries of a topic area, (2) outline what is already known and identify gaps in existing research, and (3) map existing literature of existing evidence. ${ }^{14}$ This scoping review aims to (1) outline what is already known about the role of physical activity in all stages of MM (2) map the literature on physical activity and MM and (3) identify future directions for research.

\section{METHODS AND ANALYSIS}

\section{General framework for scoping review and initial search criteria}

The main stages for a scoping review stated in Levac et $a l^{15}$ were followed (1) Identify the research question, (2) Identify relevant studies, (3) Study selection, (4) Charting the data, (5) Collating, summarising and reporting the results. The initial question was "what is known about the role of physical activity in all stages of MM (prevention and survivorship)." Studies including the MM precursor SMM were included since individuals have a 10-20\% chance of developing MM each year.

Search criteria were then established; in order to scope and include the majority of literature the exclusion criteria were minimal and included (1) any study investigating physical functioning and not physical activity per se (2) non-human studies (3) studies not published in English, (4) and studies investigating only the benign condition Monoclonal Gammopathy of Undetermined Significance (MGUS) (since there is only a $1 \%$ chance a year of developing MM). To be included studies had to report original data, investigate physical activity per se or physical activity correlates and MM or SMM, work published in peer-reviewed academic journals, $\mathrm{PhD}$ dissertations, research reports and full conference papers were considered. Searchers were conducted in PubMed, Web of Science, SPORTdiscus and MEDLINE. MEDLINE and PubMed were both searched separately as a type of sensitivity analyses for the search terms, since PubMed is a search engine for MEDLINE; all papers identified in PubMed were identified in MEDLINE and vice versa. Search terms entered into each database are presented in table 1. Titles of identified papers were screened by one reviewer (LS) and those with titles not deemed relevant were removed. Remaining papers were then screened by two reviewers (LS and OM) against the inclusion/exclusion criteria, no disagreements occurred between reviewers on which papers to include. Reference lists of remaining papers after review were then searched to identify papers 


\begin{tabular}{|c|c|}
\hline PubMed & $\begin{array}{l}\text { "multiple myeloma"[MeSH Terms] OR } \\
\text { ("multiple"[All Fields] AND "myeloma"[All } \\
\text { Fields]) OR "multiple myeloma"[All } \\
\text { Fields]) AND ("motor activity"[MeSH } \\
\text { Terms] OR ("motor"[All Fields] AND } \\
\text { "activity"[All Fields]) OR "motor } \\
\text { activity"[All Fields] }\end{array}$ \\
\hline $\begin{array}{l}\text { Web of } \\
\text { Science }\end{array}$ & $\begin{array}{l}\text { Myeloma and physical activity or exercise } \\
\text { or walking }\end{array}$ \\
\hline MEDLINE & $\begin{array}{l}\text { Multiple myeloma and physical activity or } \\
\text { exercise or walking }\end{array}$ \\
\hline SportsDiscuss & $\begin{array}{l}\text { Multiple myeloma and physical activity or } \\
\text { exercise or walking }\end{array}$ \\
\hline
\end{tabular}

missed in electronic searches, and reference lists of those papers, and so on until no further papers could be identified.

\section{RESULTS}

Searches were carried out in May 2015. First the search engine PubMed was searched and 35 papers were identified, of which 13 were entered into full-text review. Next, Web of Science was searched and 134 papers were identified, of which an additional four, previously unidentified papers, were entered into full-text review. We then searched SPORTdiscuss and MEDLINE combined, 53 papers were identified and two additional papers (identified by SPORTdiscuss) were incorporated. A total of 19 papers were reviewed, 5 of these papers were excluded, 1 paper examined only physical functioning and not physical activity, another paper did not investigate MM or SMM per se, 1 paper did not distinguish MM from other haematological cancers, another was a letter and one was the reporting of a protocol. Finally, we searched reference lists of papers and no further studies were included. A total of 14 papers were included in this review. See figure 1 for flow of citations.

The following information was extracted from each paper: Title, author, year of publication, study design, study aim and key findings (tables 2-4). If the information was not available from the abstract the appropriate information was extracted from the full text. Findings from scoping the literature are presented as stage of cancer journey (prevention and survivorship). Results for MM and SMM are reported separately.

\section{Prevention}

This review identified three journal articles relating to the role of physical activity in the prevention of MM (table 2). All studies were of a prospective cohort design with $11,{ }^{16} 15^{17}$ and 22 years ${ }^{18}$ follow-up, these studies produced mixed results. Two studies ${ }^{16}{ }^{18}$ found no associations between baseline physical activity and incident MM. One study found that for men and women walking less than $30 \mathrm{~min}$ a day at baseline,

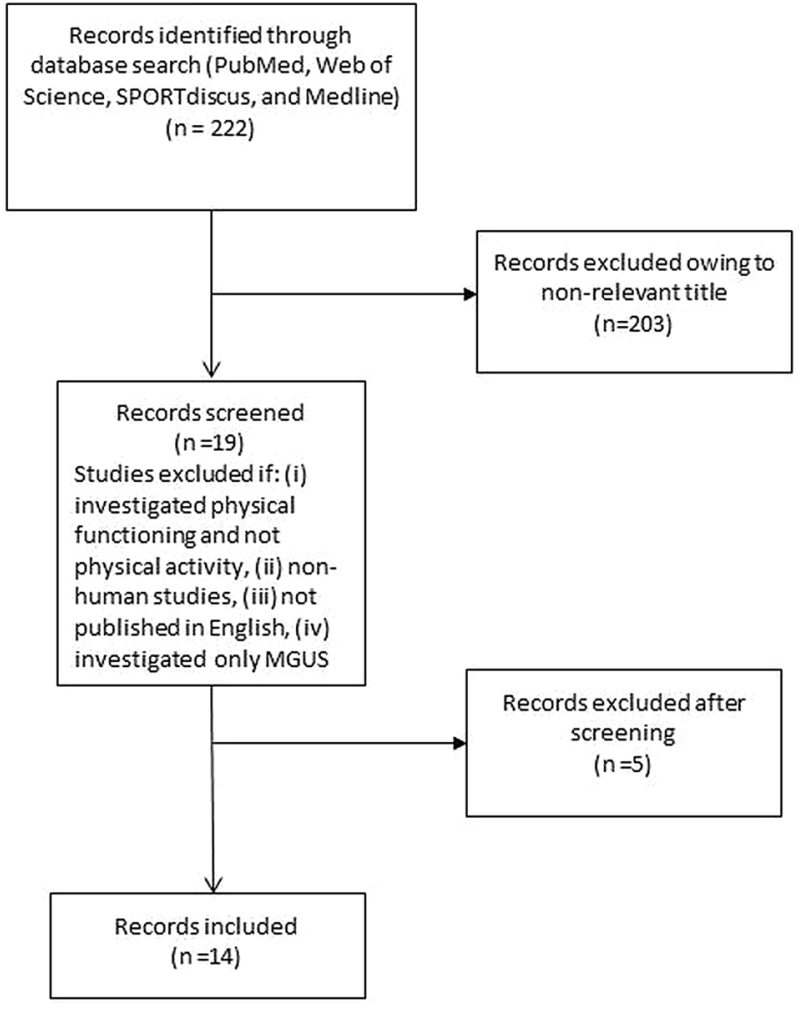

Figure 1 Flow chart of citations. MGUS, Monoclonal Gammopathy of Undetermined Significance.

compared to walking greater than $30 \mathrm{~min}$ a day, was associated with increased age and sex-adjusted MM risk $(\mathrm{HR}=2.0 ; 95 \%$ CI 1.2 to 3.4$) .{ }^{17}$

\section{Survivorship}

Nine papers were identified that addressed physical activity during, or after, treatment for MM, of which three used a qualitative design,${ }^{19-21}$ three used a randomised controlled trial (RCT) ${ }^{22-24}$ one was a single arm pilot study, ${ }^{25}$ and two were cross-sectional ${ }^{26}{ }^{27}$ (tables 3 and 4).

The qualitative studies aimed to identify barriers and facilitators to physical activity in patients with MM. Barriers to physical activity predominately related to the symptoms of MM and side effects of therapy, including pain, fatigue and fear of infection. Low self-motivation was also a barrier. Women participated in a more diverse range of physical activities than men and there were gender differences in preferred type of physical activity. Women were more likely to report psychological and social benefits; whereas men reported physical activity as a way to keep busy and self-motivation was a barrier. Patients treated with an autologous stem cell transplant more often reported affective benefits of participation in physical activity and fatigue as a barrier. Patients treated with other (non-transplant related) therapies (eg, chemotherapy, radiotherapy) were more likely to report pain as a barrier. Commitment to keeping their promise to exercise helped patients to continue their exercise 


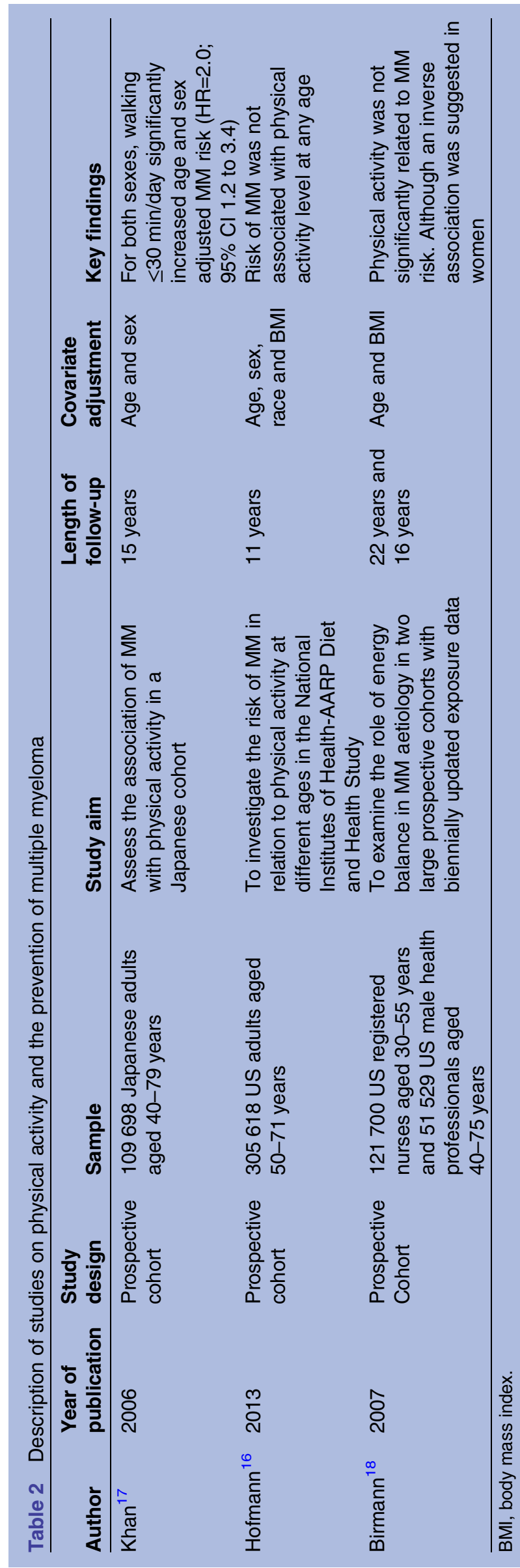

programme during times when they were not feeling well. Encouragement from family and healthcare professionals was reported to facilitate adherence to an exercise programme. Patients reported needing to reduce the exercise intensity or take time off from exercise immediately following chemotherapy.

One cross-sectional study ${ }^{26}$ aimed to examine the differences between prediagnosis and postdiagnosis levels of physical activity using retrospective recall, perceived barriers and likelihood of attending a physical activity programme, and factors that influence whether or not respondents are meeting physical activity guidelines. The study found that significantly more people reported meeting the physical activity guideline of $150 \mathrm{~min}$ of moderate-to-vigorous activity per week prediagnosis than post. Those who participated in sufficient levels of physical activity prior to diagnosis were approximately five times more likely to meet physical activity guidelines postdiagnosis, compared to people who did not meet guidelines prior to diagnosis. Reported perceived barriers to physical activity participation were fatigue, injuries, pain, other health conditions, age-related decline in physical ability, lack of knowledge on physical activities that are safe, cost of exercise, nausea, no one to exercise with and lack of time. The other cross-sectional study examined the association between physical activity and quality of life in MM survivors. It was found that $6.8 \%$ and $20.4 \%$ of survivors met physical activity guidelines during active and off treatment periods, respectively. Participation in physical activity was found to be positively associated with overall quality of life. ${ }^{27}$

The single arm pilot study explored the feasibility and patient outcomes of a tailored, physiotherapist-led exercise programme, consisting of stretching, strength and resistance, and aerobic exercise, in treated MM survivors. ${ }^{25}$ This exercise programme was found to be feasible and safe with no adverse reactions to exercise reported. Uptake to the exercise programme and attendance rates were high indicating willingness to engage and strong adherence to the physical activity intervention. Benefits were demonstrated in patient reported quality of life and improvements in upper and lower limb strength.

One RCT aimed to determine the effect of epoetin therapy with and without a home-based individualised exercise programme that incorporated stretching, aerobic and strength resistance training for patients being treated with high-dose chemotherapy and autologous peripheral blood stem cell transplantation for MM. ${ }^{22}$ The study found that recovery and treatment response were not significantly different between groups after transplantation. However, the exercise group had significantly fewer red blood cell transfusions and fewer attempts at stem cell collection. Another RCT ${ }^{23}$ aimed to compare usual care with a home-based individualised exercise programme, consisting of stretching, strength and resistance, and aerobic exercise, in patients receiving intensive treatment for $\mathrm{MM}$ and epoetin alfa therapy. No differences were found between the 
Table 3a Description of qualitative and cross-section studies on physical activity and multiple myeloma survivorship

\begin{tabular}{|c|c|c|c|c|}
\hline Author & $\begin{array}{l}\text { Year of } \\
\text { publication }\end{array}$ & Study design & Study aim & Key findings \\
\hline Craike $^{21}$ & 2013 & $\begin{array}{l}\text { Qualitative semistructure } \\
\text { telephone interview }\end{array}$ & $\begin{array}{l}\text { To gain an in-depth understanding of } \\
\text { the physical activity experiences and } \\
\text { perceived benefits and barriers to } \\
\text { physical activity for patients with MM }\end{array}$ & $\begin{array}{l}\text { Barriers to physical activity predominately related to the symptoms of } \\
\text { MM and side effects of therapy, including pain, fatigue and fear of } \\
\text { infection } \\
\text { Low self-motivation was also a barrier } \\
\text { Women participated in a more diverse range of physical activities than } \\
\text { men and there were gender differences in preferred type of physical } \\
\text { activity } \\
\text { Women were more likely to report psychological and social benefits; } \\
\text { whereas men reported physical activity as a way to keep busy and } \\
\text { self-motivation was a barrier }\end{array}$ \\
\hline Coon $^{19}$ & 2004 & $\begin{array}{l}\text { Qualitative-face to face } \\
\text { interviews of intervention } \\
\text { participants in RCT }\end{array}$ & $\begin{array}{l}\text { The aim of this study was to } \\
\text { understand how participants decide } \\
\text { when to start, interrupt, stop or resume } \\
\text { an exercise programme or adjust the } \\
\text { intensity. And to understand what } \\
\text { helped or hindered the participants' } \\
\text { ability to do exercises }\end{array}$ & $\begin{array}{l}\text { Intrinsic factors that facilitated exercise adherence included a belief that } \\
\text { exercise would be beneficial, a personal moral/ethical philosophy with } \\
\text { regard to honouring a commitment and/or taking responsibility for one's } \\
\text { health, and personal strategies such as keeping a routine and setting } \\
\text { goals } \\
\text { Extrinsic facilitators included having a good support system and } \\
\text { receiving prophylactic epoetin alfa }\end{array}$ \\
\hline Coon $^{20}$ & 2004 & $\begin{array}{l}\text { Qualitative interviews- } \\
\text { naturalistic } \\
\text { (constructionists) of } \\
\text { participants taking part in } \\
\text { an exercise programme }\end{array}$ & $\begin{array}{l}\text { To ascertain how patients with MM } \\
\text { appraised the experience of } \\
\text { participating in a home-based exercise } \\
\text { intervention as part of a RCT of } \\
\text { prophylactic epoetin alfa with or without } \\
\text { exercise }\end{array}$ & $\begin{array}{l}\text { Patients with MM can safely carry out a home-based exercise } \\
\text { programme aimed at reducing cancer-related fatigue } \\
\text { Commitment to keeping their promise to exercise helped participants to } \\
\text { continue their exercise programme during times when they were not } \\
\text { feeling well } \\
\text { Encouragement from family and healthcare professionals facilitates } \\
\text { adherence to an exercise programme } \\
\text { Many participants avoided taking time off from exercise because they } \\
\text { had experienced dramatic declines in their strength and stamina after } \\
\text { interruptions to their exercise programme However, most patients } \\
\text { needed to reduce the exercise intensity or take time off from exercise } \\
\text { immediately following chemotherapy }\end{array}$ \\
\hline Craike $^{26}$ & 2013 & $\begin{array}{l}\text { Cross-sectional survey, } \\
\text { including retrospective } \\
\text { recall }\end{array}$ & $\begin{array}{l}\text { To examine, for people treated for MM, } \\
\text { (1) differences between prediagnosis } \\
\text { and postdiagnosis levels of physical } \\
\text { activity, (2) perceived barriers and } \\
\text { likelihood of attending a physical } \\
\text { activity programme and (3) factors that } \\
\text { influence whether or not respondents } \\
\text { are meeting physical activity guidelines }\end{array}$ & $\begin{array}{l}\text { Significantly more people were meeting physical activity guidelines } \\
\text { prediagnosis }(38.9 \%) \text { than currently }(20.1 \%) \\
\text { The strongest perceived barrier was fatigue }(37.8 \%) \text {, followed by } \\
\text { injuries }(34.2 \%) \text {, pain }(28.1 \%) \text {, other health conditions }(21.1 \%) \text { and } \\
\text { age-related decline in physical ability }(18.5 \%) \text {. Lack of knowledge about } \\
\text { physical activities that are safe }(19.7 \%), \text { lack of confidence in physical } \\
\text { ability }(17.1 \%) \text { and fear or injury }(16.2 \%) \text { were also reported } \\
\text { Perceived barriers relating to interpersonal factors were least likely to be } \\
\text { reported as barriers to participation, including nausea }(7.9 \%) \text {, cost of } \\
\text { exercise }(9.2 \%), \text { no one to exercise with }(10.1 \%) \text {, and lack of time } \\
(10.1 \%)\end{array}$ \\
\hline
\end{tabular}

\section{Author}

Qualitative semistructure

To gain an in-depth understanding of

sical activity experiences and

perceived benefits and barriers to

physical activity for patients with MM health, and personal strategies such as keeping a routine and setting

receiving prophylactic epoetin alfa

(constructionists) o participants taking part in an exercise programme

prophylactic epoetin alfa with or without adherence to an exercise programme interruptions to their exercise programme However, mi needed to reduce the exercise intensity or take time off from exercise

including retrospective (1) differences between prediagnosis and postdiagnosis levels of physical activity, (2) perceived barriers and likelihood of attending a physica activity programme and (3) factors that influence whether or not respondents Perceived barriers relating to interpersonal factors were least likely to be reported as barriers to participation, including nausea (7.9\%), cost of $(10.1 \%)$ 


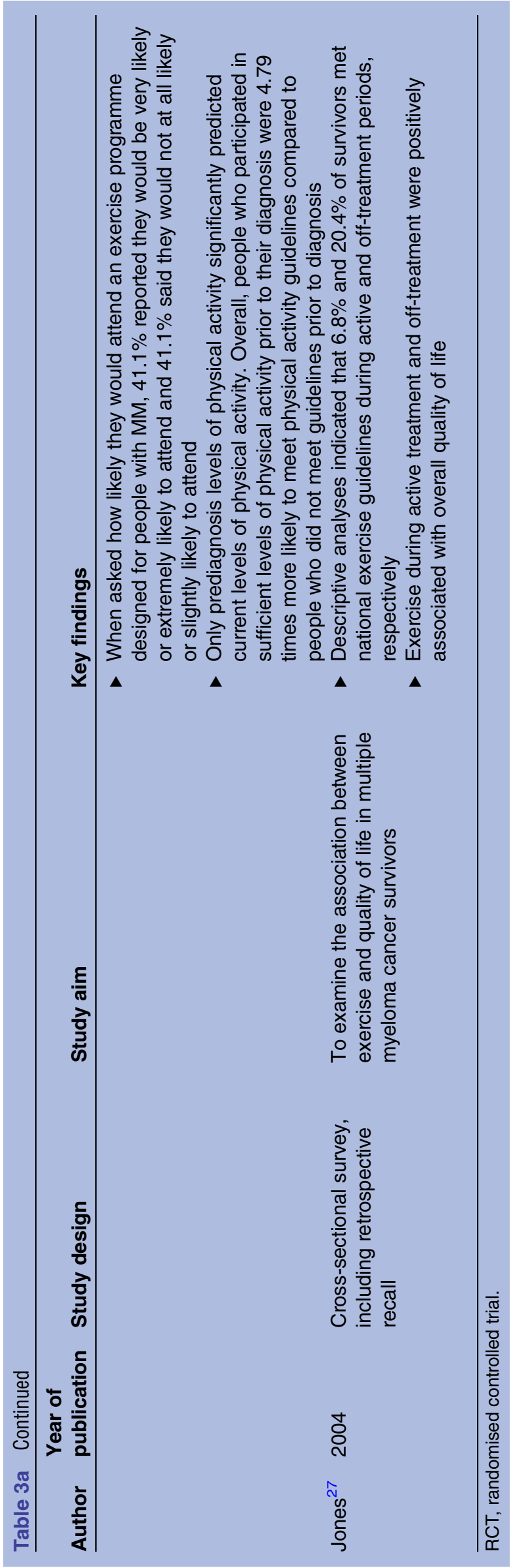

experimental and control groups for fatigue, sleep or performance (aerobic capacity). However, exercise combined with epoetin alfa helped alleviate anaemia. One RCT $^{24}$ included participants receiving high-dose chemotherapy and autologous peripheral blood stem cell transplantation and tested the feasibility of home-based exercise therapy (consisting of similar exercises to those previously mentioned). The study found that those assigned to the exercise group experienced a significant increase in lean body weight compared to the nonexercise group. Moreover, the study suggests that an exercise programme for patients receiving aggressive treatment for MM is feasible and may be effective in decreasing fatigue and mood disturbance while improving sleep.

\section{Physical activity and SMM}

The scoping review identified just two papers on SMM and physical activity, both of these were case reports on the same female patient with SMM. One case study aimed to document heart rate variability during a 6-week period in a female patient with SMM who was currently performing a high-intensity training programme. ${ }^{28}$ The patient with SMM recorded similar heart rate variability to that of six age-matched controls. The other case study ${ }^{29}$ aimed to evaluate the influence of a training programme on changes in serum monoclonal protein level, percentage of bone marrow plasma cells, fitness performance and cardiac autonomic control. The case study reports that exercise performance in all fitness components improved while serum monoclonal protein levels and percentage of bone marrow plasma cells decreased. Moreover, time and frequency domain heart rate variability parameters exhibited significant increases with heart rate complexity remaining the same.

\section{DISCUSION}

This scoping review has highlighted that to date there has been little research on physical activity for MM and even less for SMM. The literature that does exist on the role of physical activity in the prevention of $\mathrm{MM}$ is inconclusive and much more epidemiological research is needed in this area using larger samples and prospective cohort designs. We encourage those in the process of designing new cohort studies to allow for future investigation of such longitudinal associations.

This review has identified numerous suggested social, sociodemographic and biomedical barriers and facilitators to physical activity in patients with MM. Identified barriers and facilitators suggest that gender and treatment-specific physical activity interventions may yield the best results. We recommend that future research should test this hypothesis. Furthermore, those who have low levels of physical activity prediagnosis may benefit the most from physical activity interventions. More research is needed to investigate the 


\begin{tabular}{|c|c|c|c|c|}
\hline Author & $\begin{array}{l}\text { Year of } \\
\text { publication }\end{array}$ & Study design & Study aim & Key findings \\
\hline Coleman $^{23}$ & 2012 & $\begin{array}{l}\text { RCT with repeated measures } \\
\text { 15-week intervention period } \\
\text { Intervention consisted of stretching, } \\
\text { strength and resistance, and aerobic } \\
\text { exercise (frequency of exercise } \\
\text { sessions and duration is not reported) }\end{array}$ & $\begin{array}{l}\text { To compare usual care with a home-based } \\
\text { individualised exercise programme (HBIEP) in } \\
\text { patients receiving intensive treatment for MM } \\
\text { and epoetin alfa therapy }\end{array}$ & $\begin{array}{l}\text { No statistically significant differences } \\
\text { existed among the experimental and } \\
\text { control groups for fatigue, sleep or } \\
\text { performance (aerobic capacity) }(\mathrm{p}>0.05) \\
\text { Exercise combined with epoetin alfa } \\
\text { helped alleviate anaemia }\end{array}$ \\
\hline Coleman ${ }^{22}$ & 2008 & $\begin{array}{l}\text { RCT } \\
\text { In-week intervention period } \\
\text { strength and resistance, and aerobic } \\
\text { exercise (frequency of exercise } \\
\text { session and duration is not reported) }\end{array}$ & $\begin{array}{l}\text { To determine the effect of epoetin therapy (short } \\
\text { term vs long term) with and without a } \\
\text { home-based individualised exercise programme } \\
\text { that incorporated aerobic and strength } \\
\text { resistance training for patients being treated with } \\
\text { high-dose chemotherapy and autologous } \\
\text { peripheral-blood stem cell transplantation for } \\
\text { MM }\end{array}$ & $\begin{array}{l}\text { Recovery and treatment response were } \\
\text { not significantly different between groups } \\
\text { after transplantation } \\
\text { The exercise group had significantly fewer } \\
\text { red blood cell transfusions and fewer } \\
\text { attempts at stem cell collection }(p<0.025) \\
\text { Serious adverse events were similar in } \\
\text { each group ( } p>0.05)\end{array}$ \\
\hline Coleman $^{24}$ & 2003 & $\begin{array}{l}\text { RCT } \\
\text { Intervention period, session frequency } \\
\text { and duration is not reported } \\
\text { Intervention consisted of stretching, } \\
\text { strength and resistance, and aerobic } \\
\text { exercise }\end{array}$ & $\begin{array}{l}\text { To test the feasibility of home-based exercise } \\
\text { therapy for patients receiving high-dose } \\
\text { chemotherapy and autologous peripheral blood } \\
\text { stem cell transplantation as treatment for MM }\end{array}$ & $\begin{array}{l}\text { Individuals assigned to exercise gained an } \\
\text { average lean body weight of } 0.40 \mathrm{~kg} \text { per } \\
\text { month } \\
\text { The non-exercise group experienced and } \\
\text { average decline in lean body weight of } \\
-0.44 \mathrm{~kg} / \text { month ( } p<0.01 \text { ) } \\
\text { The study suggests that an exercise } \\
\text { programme for patients receiving } \\
\text { aggressive treatment for MM is feasible } \\
\text { and may be effective in decreasing fatigue } \\
\text { and mood disturbance while improving } \\
\text { sleep }\end{array}$ \\
\hline Groeneveldt $^{25}$ & 2013 & $\begin{array}{l}\text { Single arm pilot study } \\
\text { 6-month intervention period } \\
\text { Intervention consisted of taking part in } \\
\text { stretching, strength and resistance, } \\
\text { and aerobic exercise three times a } \\
\text { week }\end{array}$ & $\begin{array}{l}\text { To assess the feasibility (accrual rate, } \\
\text { acceptability and adherence) and safety of an } \\
\text { exercise programme for MM survivors }\end{array}$ & $\begin{array}{l}\text { The exercise programme was feasible and } \\
\text { safe for patients with MM and there was } \\
\text { high attendance and acceptability } \\
\text { Benefits were evident in patients reported } \\
\text { outcomes of QOL, fatigue and measured } \\
\text { muscle strength (all } p<0.01 \text { ) }\end{array}$ \\
\hline
\end{tabular}

$\mathrm{RCT}$, randomised controlled trial; QOL, quality of life. 
Table 4 Description of studies on physical activity and smouldering multiple myeloma

\begin{tabular}{|c|c|c|c|c|}
\hline Author & $\begin{array}{l}\text { Year of } \\
\text { publication }\end{array}$ & $\begin{array}{l}\text { Study } \\
\text { design }\end{array}$ & Study aim & Key findings \\
\hline Boullosa $^{28}$ & 2010 & $\begin{array}{l}\text { Case } \\
\text { Report }\end{array}$ & $\begin{array}{l}\text { To document heart rate variability (HRV) } \\
\text { during a } 6 \text {-week period in a female SMM } \\
\text { patient that was currently performing a } \\
\text { high-intensity training programme }\end{array}$ & $\begin{array}{l}\text { The major finding was the reported similar } \\
\text { HRV for a highly physically active young } \\
\text { SMM patient to that of age-matched } \\
\text { controls }\end{array}$ \\
\hline Boullosa ${ }^{29}$ & 2013 & $\begin{array}{l}\text { Case } \\
\text { Report }\end{array}$ & $\begin{array}{l}\text { To evaluate the influence of a } \\
\text { supervised training programme on the } \\
\text { changes in serum monoclonal protein } \\
\text { level (ie, lgG), percentage of bone } \\
\text { marrow plasma cells (BMPCs), fitness } \\
\text { performance and cardiac autonomic } \\
\text { control (ie, HR variability (HRV) and HR } \\
\text { complexity (HRC) in a female diagnosed } \\
\text { with SMM }\end{array}$ & $\begin{array}{l}\text { Exercise performance in all fitness } \\
\text { components was improved while IgG } \\
\text { levels and BMPCs decreased from } 20 \% \\
\text { to } 10 \% \text {, respectively } \\
\text { Time and frequency domain HRV } \\
\text { parameters exhibited significant increases } \\
\text { (18\%-29\%) with HRC remaining } \\
\text { unchanged } \\
\text { The current case report results indicated } \\
\text { that a multimodal training programme } \\
\text { designed for the development of various } \\
\text { physical capacities improved exercise } \\
\text { performance, haematological function and } \\
\text { cardiac autonomic control that may } \\
\text { improve long-term prognosis for SMM }\end{array}$ \\
\hline
\end{tabular}

generalisability of the identified barriers and facilitators to other populations of patients with MM, and longitudinal studies to address associations are encouraged.

There is limited evidence using RCTs to evaluate the impact of physical activity on health parameters in patients with MM during and after treatment, although it appears to be safe and accepted by patients. Existing evidence from RCTs suggests physical activity may aid in various MM treatments and alleviate some comorbidities. When reviewing the literature one protocol of an ongoing study was identified that aims to determine the effectiveness of an individualised high-intensity strength and interval training programme with respect to physiological and psychological status in patients with MM, who have recently undergone high-dose chemotherapy followed by autologous stem cell transplantation, using a RCT. ${ }^{30}$ Future research should include RCTs to evaluate the impact of different types, frequencies and intensities of physical activity (eg, aerobic or anaerobic) on various health parameters in patients with MM (eg, fatigue, quality of life, sarcopenic obesity, bone health and anaemia). Of specific interest may be the effect of physical activity on the toxicities experienced by patients receiving anti-MM therapies, as well as the effect of particular drugs or treatment regimens on levels of physical activity. Such questions will become increasingly important with the improved survival of patients with MM, and the trend towards extended therapy. However, it should be noted that one important concern with $\mathrm{MM}$ in regard to physical activity is the fracture risk related to bone lesions. A fracture risk assessment should be carried out on a patient with MM prior to being given permission to be physically active. This has been performed in the past using radiographs in combination with Mirel's score. For example, in a recent study by Groeneveldt $e t a l$, radiographs were assessed for fracture risk by a multidisciplinary team of musculoskeletal radiologist, clinical oncologist, myeloma specialists, physiotherapist and clinical nurse specialists. Patients considered to be at risk of fractures, for example, with large lytic lesions of the long bones or extensive lytic disease in the pelvis, underwent cross-sectional imaging with CT or MRI and were referred for surgery and/or radiotherapy. Those not at risk were recommended for exercise, while some of those at risk underwent surgical fixation before embarking on the exercise programme. ${ }^{25}$

Only two studies were identified in the area of SMM and physical activity. However, inferences should not be drawn from two case studies on a single patient with SMM. This is an understudied research area and one that requires epidemiological investigation.

This is the first review of literature on physical activity and MM and SMM. The variety of search databases utilised, as well as extensive reference searches, reduced the risk of bias. However, there is a potential influence of publication bias, with negative and null findings remaining in the 'file drawer.' This review is limited by a shortage of research and it should be noted that further data may exist. This review did not include studies in which MM was pooled with other haematological cancers. $^{31} 32$ Moreover, the use of additional search terms may have identified other relevant papers.

\section{CONCLUSION}

The literature surrounding MM and SMM and physical activity is limited. Much more research is needed in all areas of MM and SMM and physical activity to 
understand the true benefit of physical activity for this population. We encourage those in the process of designing new cohort studies to allow for future assessment of associations between physical activity and onset MM and SMM, as well as the potential role physical activity plays in the transition from SMM to MM. Second, we encourage the design and investigation of gender and treatment-specific physical activity interventions in patients with MM. Finally, we highlight the need for more RCTs to evaluate the impact of different types, frequencies and intensities of physical activity on various health parameters in patients with MM.

\section{Acknowledgements In memory of Professor Jane Wardle (1950 - 2015).}

Contributors LS and OMcC carried out the review of the literature. LS drafted the manuscript. LS, OMcM, MH, BP, JW, KY and AF assisted in interpreting the data and drafting the manuscript. $\mathrm{LS}, \mathrm{OMcM}, \mathrm{MH}, \mathrm{BP}, \mathrm{JW}, \mathrm{KY}$ and $\mathrm{AF}$ read and approved the final manuscript.

Funding The authors would like to thank the Cancer Research UK (grant number C1418/A141) for funding this work.

Competing interests None declared.

Provenance and peer review Not commissioned; externally peer reviewed.

Data sharing statement No additional data are available.

Open Access This is an Open Access article distributed in accordance with the terms of the Creative Commons Attribution (CC BY 4.0) license, which permits others to distribute, remix, adapt and build upon this work, for commercial use, provided the original work is properly cited. See: http:// creativecommons.org/licenses/by/4.0/

\section{REFERENCES}

1. Gozzetti A, Candi V, Papini G, et al. Therapeutic advancements in multiple myeloma. Front Oncol 2014;4:241.

2. Kumar SK, Dispenzieri A, Lacy MQ, et al. Continued improvement in survival in multiple myeloma: changes in early mortality and outcomes in older patients. Leukemia 2014;28:1122-8.

3. Blade J, Rosinol L. Complications of multiple myeloma. Hematol Oncol Clin North Am 2007;21:1231-46, xi.

4. Rajkumar SV. MGUS and smoldering multiple myeloma: update on pathogenesis, natural history, and management. Hematology Am Soc Hematol Educ Program 2005:340-5.

5. Monninkhof EM, Elias SG, Vlems FA, et al. Physical activity and breast cancer: a systematic review. Epidemiology 2007;18:137-57.

6. Tardon A, Lee WJ, Delgado-Rodriguez M, et al. Leisure-time physical activity and lung cancer: a meta-analysis. Cancer Causes Control 2005;16:389-97.

7. Lee IM. Physical activity and cancer prevention-data from epidemiologic studies. Med Sci Sports Exerc 2003;35:1823-7.

8. Jochem C, Leitzmann MF, Keimling M, et al. Physical activity in relation to risk of hematologic cancers: a systematic review and meta-analysis. Cancer Epidem Biomar 2014;23:833-46.

9. Doyle C, Kushi LH, Byers T, et al., 2006 Nutrition, Physical Activity and Cancer Survivorship Advisory Committee; American Cancer Society. Nutrition and physical activity during and after cancer treatment: an American Cancer Society guide for informed choices. CA Cancer J Clin 2006;56:323-53.

10. Speck RM, Courneya KS, Masse LC, et al. An update of controlled physical activity trials in cancer survivors: a systematic review and meta-analysis. J Cancer Surviv 2010;4:87-100.
11. Friedenreich CM. Physical activity and breast cancer: review of the epidemiologic evidence and biologic mechanisms. Recent Results Cancer Res 2011;188:125-39.

12. Sun JY, Shi L, Gao XD, et al. Physical activity and risk of lung cancer: a meta-analysis of prospective cohort studies. Asian Pac J Cancer Prev 2012;13:3143-7.

13. Thorsen L, Courneya KS, Stevinson C, et al. A systematic review of physical activity in prostate cancer survivors: outcomes, prevalence, and determinants. Support Care Cancer 2008;16:987-97.

14. Davis K, Drey N, Gould D. What are scoping studies? A review of the nursing literature. Int J Nurs Stud 2009;46:1386-400.

15. Levac D, Colquhoun H, O'Brien KK. Scoping studies: advancing the methodology. Implement Sci 2010;5:69.

16. Hofmann JN, Moore SC, Lim U, et al. Body mass index and physical activity at different ages and risk of multiple myeloma in the NIH-AARP Diet and Health Study. Am J Epidemiol 2013;177:776-86.

17. Khan MM, Mori M, Sakauchi F, et al. Risk factors for multiple myeloma: evidence from the Japan Collaborative Cohort (JACC) study. Asian Pac J Cancer Prev 2006;7:575-81.

18. Birmann BM, Giovannucci E, Rosner B, et al. Body mass index, physical activity, and risk of multiple myeloma. Cancer Epidem Biomar 2007;16:1474-8.

19. Coon SK, Coleman EA. Exercise decisions within the context of multiple myeloma, transplant, and fatigue. Cancer Nurs 2004;27:108-18.

20. Coon SK, Coleman EA. Keep moving: patients with myeloma talk about exercise and fatigue. Oncol Nurs Forum 2004;31:1127-35.

21. Craike MJ, Hose K, Courneya KS, et al. Perceived benefits and barriers to exercise for recently treated patients with multiple myeloma: a qualitative study. BMC Cancer 2013;13:319.

22. Coleman EA, Coon SK, Kennedy RL, et al. Effects of exercise in combination with epoetin alfa during high-dose chemotherapy and autologous peripheral blood stem cell transplantation for multiple myeloma. Oncol Nurs Forum 2008;35:E53-61.

23. Coleman EA, Goodwin JA, Kennedy R, et al. Effects of exercise on fatigue, sleep, and performance: a randomized trial. Oncol Nurs Forum 2012;39:468-77.

24. Coleman EA, Coon S, Hall-Barrow J, et al. Feasibility of exercise duration treatment for multiple myeloma. Cancer Nurs 2003;26:410-19.

25. Groeneveldt L, Mein G, Garrod R, et al. A mixed exercise training programme is feasible and safe and may improve quality of life and muscle strength in multiple myeloma survivors. BMC Cancer 2013;13:31.

26. Craike M, Hose K, Livingston PM. Physical activity participation and barriers for people with multiple myeloma. Support Care Cancer 2013;21:927-34.

27. Jones L, Courneya K, Vallance J, et al. Association between exercise and quality of life in multiple myeloma cancer survivors. Support Cancer Care 2004;12:780-8.

28. Boullosa DA, Leicht AS, Tuimil JL. Impact of fire-fighters training on a female with smoldering multiple myeloma. J Sport Med Phys Fit 2010:50:326-9.

29. Boullosa DA, Abreu L, Tonello L, et al. Exercise is medicine: case report of a woman with smoldering multiple myeloma. Med Sci Sports Exerc 2013;45:1223-8.

30. Persoon S, Kersten MJ, Chinapaw MJ, et al. Design of the EXercise Intervention after Stem cell Transplantation (EXIST) study: a randomized controlled trial to evaluate the effectiveness and cost-effectiveness of an individualized high intensity physical exercise program on fitness and fatigue in patients with multiple myeloma or (non-) Hodgkin's lymphoma treated with high dose chemotherapy and autologous stem cell transplantation. BMC Cancer 2010;10:671.

31. Dimeo F, Tilmann M, Bertz $\mathrm{H}$, et al. Aerobic exercise in the rehabilitation of cancer patients after high dose chemotherapy and autologous peripheral stem cell transplantation. Cancer 1997;79:1717-22.

32. Hayes S, Davies P, Parker T, et al. Quality of life changes following peripheral blood stem cell transplantation and participation in a mixed-type, moderate intensity, exercise program. Bone Marrow Transplant 2004;33:553-8. 


\section{Correction}

Smith L, McCourt O, Henrich M, et al. Multiple myeloma and physical activity: a scoping review. BMJ Open 2015;5:e009576. doi:10.1136/bmjopen-2015-009576corr1

The surname of the third author was spelt incorrectly. The third author's name is Malgorzata Heinrich.

BMJ Open 2016;6:e009576corr1. doi:10.1136/bmjopen-2015-009576corr1 